\title{
EFFECT OF TWO DIFFERENT ROOT CANAL INSTRUMENTS ON REMOVAL OF ENDOTOXINS FROM NECROTIC ROOT CANALS. (A RANDOMIZED CLINICAL TRIAL)
}

\author{
Marwa Mahmoud Bedier* and Heba Ahmed ElAsfouri**
}

\begin{abstract}
Aim of the study: The aim of the present randomized clinical study was to evaluate the effect of OneShape and Protaper Next rotary system on the removal of endotoxins from teeth with asymptomatic necrotic pulp.

Materials and Methods: Thirty patients were randomly allocated into two groups $(n=15)$ according to the type of rotary system used in mechanical preparation; either Group OS (OneShape) or Group PN (Protaper Next). Samples were taken before and after mechanical preparation and quantification of endotoxins was done using Human Elisa kit. Statistical analyses were performed using Mann-Whitney $U$ test to compare between the two groups then Wilcoxon signed- rank test was used to study the changes after treatment within each group. The significance level was set at $\mathrm{P} \leq 0.05$
\end{abstract}

Results: Group OS, showed a statistically significant reduction in endotoxins levels after treatment $(\mathrm{P}$-value $<0.001$, Effect size $=0.880)$. In Group PN, there was a statistically significant reduction in endotoxins levels after treatment $(\mathrm{P}$-value $<0.001$, Effect size $=0.931)$ and Group OS showed statistically significant lower median \% reduction in endotoxins level than Group PN.

Conclusion: Protaper Next was more effective than the Oneshape in reducing the endotoxins from teeth with asymptomatic necrotic pulp.

KEYWORDS: Multiple-file; Necrotic; OneShape; Protaper Next; Root canal; Single-file.

\section{INTRODUCTION}

The main goal of endodontic treatment is to reduce the load of microorganisms and their byproducts from the root canal system and prevent them from reaching the periapical region, thus promote ideal conditions for periapical healing ${ }^{[1]}$.
Gram-negative anaerobic bacteria are the predominant species in primary endodontic infection, with lipopolysaccharide (LPS), known as endotoxin ${ }^{[2]}$ on their cell walls. Endotoxin is composed of polysaccharides, lipids and proteins, where lipid $\mathrm{A}$ is responsible for its toxic effects.

\footnotetext{
* Associate Professor of Endodontics , Endodontic Department, Faculty of Dentistry, Cairo University, Egypt.

** Lecturer of Endodontics , Endodontic Department, Faculty of Dentistry, Cairo University, Egypt.
} 
LPS is released during disintegration of bacteria after multiplication or death ${ }^{[3]}$. It does not cause cell or tissue damage directly, but they stimulate the competent cells to release the chemical mediators, causing a series of biological effects, which lead to an inflammatory reaction and periapical bone resorption ${ }^{[4]}$.

Although endotoxin has been reported in samples taken from root canals with pulp necrosis [5], correlation has been detected between the presence of endotoxins in the root canal system and the clinical endodontic signs and symptoms such as spontaneous pain, tenderness to percussion, pain on palpation, exudation and presence of periapical radiolucent areas ${ }^{[6]}$.

Several studies evaluated the effect of chemomechanical preparation in reducing the bacterial load in the root canal system, and reported that mechanical action of the instruments is responsible for more than $95 \%$ of the bacterial reduction ${ }^{[7-9]}$.

In modern endodontic practice, the continuous development of different nickel titanium (NiTi) rotary systems for root canal preparation, is aiming to reduce the procedural errors, preparation time, operator fatigue, produce more centered preparations ${ }^{[10]}$, with less apical extrusion of debris ${ }^{[11]}$. This is achieved by changing the instrument alloy, design, surface treatment, rotational speed, kinematics, and the manufacturing process.

Recently, ProTaper Next rotary system (Dentsply Maillefer, Ballaigues, Switzerland), has been manufactured from M-wire with substantially stable martensite phase under clinical conditions, increasing the flexibility and cyclic fatigue resistance of the files. Moreover, the off-centred rectangular cross-section design, and the unique asymmetric rotary motion enhances canal shaping efficiency, as claimed by the manufacturer ${ }^{[12]}$.

OneShape rotary NiTi single-file systems (Micromega, Besancon, France), with continuous rotary motion action and 3 different cross sections,
3 cutting edges in the apical and middle thirds and 2 cutting edges, near the shaft was introduced ${ }^{[13]}$. This design was claimed for the reduction of the preparation time and efficient cleaning ability ${ }^{[14]}$.

To our knowledge, however, there is no clinical study in the literature investigating the effectiveness of OneShape rotary file and ProTaper Next system in reducing the load of endotoxins in root canals with necrotic pulp. Thus, the purpose of the present randomized clinical study was to evaluate the percentage reduction of endotoxins after mechanical instrumentation of asymptomatic necrotic root canals using either OneShape rotary file and ProTaper Next system. The null hypothesis was that there is no significant difference in the amount of endotoxins reduction after using either OneShape rotary file and ProTaper Next system.

\section{MATERIALS AND METHODS}

\section{Trial design and Sample size calculation}

The trial design was a triple-blinded, controlled, parallel grouped randomized clinical trial and registered on www.clinicaltrials.gov with the identifier: NCT03641612. The trial was done following the guidelines of the declaration of Helsinki and approved by the Research Ethics Committee, Faculty of Dentistry, Cairo University with identifier: 18/4/32. All patients were asked to sign a printed informed consent to before participating in the study after the explanation of all the treatment procedures.

The primary outcome used for this power analysis was the percentage reduction in Endotoxins. Since there is no relevant literature that measures the percentage reduction in Endotoxins by OneShape system, it was assumed that it provides $40 \%$ reduction. Based upon the results of Protaper system obtained from Martinho et al. $2014{ }^{[15]}$, using alpha $(\alpha)$ level of $0.05(5 \%)$ and Beta $(\beta)$ level of $0.20(20 \%)$ i.e. power $=80 \%$; the minimum estimated sample size was a total of 24 subjects ( 12 subjects per group). To compensate for a drop-out rate of $20 \%$, the number 
was increased to a total of 30 subjects ( 15 subjects per group). Sample size calculation was performed using $\mathrm{G}^{*}$ Power Version 3.1.9.2.

\section{Participants selection}

\section{Inclusion and Exclusion}

Outpatients from the clinic of Endodontics, Faculty of Dentistry, Cairo University, Egypt, were diagnosed and checked for the eligibility criteria through careful medical history, dental history and clinical examination, in addition to proper intra-oral, pre-operative radiographic assessment. Patients enrolled in the study had asymptomatic singlerooted mandibular premolars diagnosed clinically and confirmed by pulp sensitivity tests as teeth with pulp necrosis, showing presence of one root canal and absence of periodontal pockets deeper than 4 mm. Only patients between 20 and 50 years old were included in this study. Exclusion criteria were: Patients who had received antibiotic treatment during the last three months or who had any general disease, previous endodontic therapy of the affected tooth, teeth diagnosed with vital pulp, abnormal anatomy and calcified canals, caries below the bony level (non-restorable tooth), or teeth with periapical pathosis or sinus tract, moreover, canals wider than a size $20 \mathrm{~K}$-file at the apex were excluded.

\section{Randomization}

The random sequence was done using block randomization (www.random.org) by a colleague and the random sequence table was kept with him. After eligibility assessment, the operator called the colleague for eligibility checking and to know the group assignment for the patients. Thirty Outpatients from the clinic of Endodontics at the Faculty of Dentistry, Cairo University, Egypt were recruited to participate in the study, and were randomly assigned into two equal groups $(n=15)$ according to the type of instruments used during root canal preparation either Group OS: OneShape rotary file or Group PN: ProTaper Next rotary system.

\section{Blinding}

The operator was not blinded, while the participants, outcome assessor and data analyst were blinded in this trial.

\section{Interventions}

\section{Sampling procedure:}

All the procedures were performed under aseptic conditions, all the instruments and materials were treated with Co 60 gamma radiation $(20 \mathrm{kGy}$ for 6 hours) for sterilization and elimination of the pre-existing endotoxins as described in previous studies $[16,17]$. The teeth were first isolated with a rubber dam, then the crown and the surrounding structures were disinfected with $30 \%$ hydrogen peroxide (volume/ volume for 30 seconds) followed by $2.5 \%$ sodium hypochlorite $(\mathrm{NaOCl})$ for another 30 seconds, then inactivated with $5 \%$ sodium thiosulfate. Access cavity preparation was done under continuous manual irrigation with sterile/apyrogenic saline solution using a sterile/ apyrogenic high-speed diamond bur. The first stage in access cavity preparation was to remove the major contaminants, including the carious lesions, then access cavity was disinfected before entering the pulp chamber, according to the same protocol described before. A new sterile/ apyrogenic bur was used with sterile/ apyrogenic saline to access the pulp chamber.

The first Pre-operative endotoxin sample (S1) was taken by introducing a \#15 sterile pyrogenfree paper point (Dentsply-Maillefer, Ballaigues, Switzerland) into the full length of the canal which was determined radiographically and kept in position for 1 minute, then immediately placed in a pyrogen-free glass and stored in $-20{ }^{\circ} \mathrm{C}$. This procedure was repeated using 5 paper points.

\section{Clinical Procedures}

After access cavity preparation and preoperative endotoxin sampling (S1), the patency of the canals was done using hand K-files size 10 and 
15 then the working length determination was done using electronic apex locater (Root ZX, J. Morita USA, Irvine, USA), which was then confirmed radiographically to $0.5-1 \mathrm{~mm}$ shorter than the radioghraphic apex.

In Group OS: OneShape rotary file (size 30, 0.06 taper) was fixed to the X-smart endodontic motor (Dentsply Maillefer, Ballaigues, Switzerland), with a preset torque level of $4 \mathrm{Ncm}$ and a constant rotation speed of $400 \mathrm{rpm}$, then used in three gentlein-and-out motions until reaching the full working length.

In Group PN: ProTaper Next rotary system was used according to the manufacturer's instructions, in continuous rotation motion, using $\mathrm{X}$-smart endodontic motor with a rotational speed of 300 rpm, and a torque of $2.0 \mathrm{Ncm}$. X1 (size 17, 0.04 taper) was introduced first into root canal without any pressure, in gentle in-and-out movements till reaching the working length, followed by X2 (size 25,0.06 taper) and finally X3 (size 30, 0.07 taper) was used in brushing action motion against the walls of the canal to the full working length.

During instrumentation, the root canals were irrigated with $5 \mathrm{ml}$ of $2.5 \% \mathrm{NaOCl}$ by using a 30-gauge side-vented needle (NaviTip, Ultradent South Jordan, UT, USA), placed within $2 \mathrm{~mm}$ from the working length. At the end of the preparation, $\mathrm{NaOCl}$ was inactivated using $5 \mathrm{ml}$ of sterile $5 \%$ sodium thiosulphate for 1 minute, which was then removed by $5 \mathrm{ml}$ of sterile/apyrogenic saline solution. The second Post-operative endotoxin sample (S2) was then taken from the root canals using sterile pyrogen-free paper point (size 30,0.06 taper) inserted into the full length of the canal using the same procedures followed in $\mathrm{S} 1$.

A radiograph was obtained to ensure proper master cone extension (size 30, taper 0.06), then the canals were dried using paper points and obturation was done using modified single cone technique using a resin based sealer (ADSEAL META BIOMED CO., LTD., Korea.). Obturation was considered complete when the spreader can no longer penetrate beyond the cervical line. Excess gutta-percha was cut off using a heated plugger and teeth were then sealed using Cavit temporary filling (3M ESPE, St Paul, MN, USA). All procedures were done in a singlevisit, checked radiographically and recorded in the procedure chart.

\section{Primary outcome measures:}

\section{Quantification of Endotoxin concentration}

Human endotoxin (ET) ELISA Kit (SandwichELISA method) was used to measure the endotoxins concentrations in the root canals before (Pre-operatively) and after (Post-operatively) chemomechanical procedures. The endotoxins were extracted from paper point by addition of 200ul of Phosphate buffered saline (PBS), then vortex for 15 seconds followed by centrifugation for $5 \mathrm{~min}$ at $3000 x$. The supernatant was used for measurement of the endotoxins by using Human endotoxin (ET) ELISA Kit provided by SunLong Biotech Co., LTD, Catalogue Number: SL0652Hu, India. This ELISA kit uses Sandwich-ELISA method, where the Micro-Elisa strip plate provided in this kit has been precoated with an antibody specific to ET. Standards or samples are added to the appropriate MicroElisa strip plate wells and combined to the specific antibody. Then, a Horseradish Peroxidase (HRP)conjugated antibody specific for ET is added to each Micro-Elisa strip plate well and incubated. Free components are washed away. The TMB substrate solution is added to each well. Only those wells that contain ET and HRP conjugated ET antibody will appear blue in color and then turn yellow after the addition of the stop solution. The optical density (OD) is measured spectrophotometrically at a wavelength of $450 \mathrm{~nm}$. The OD value is proportional to the concentration of ET. The concentration of ET in the samples was calculated by comparing the OD of the samples to the standard curve. 


\section{Statistical analysis}

Numerical data were explored for normality by checking the distribution of data and using tests of normality (Kolmogorov-Smirnov and Shapiro-Wilk tests). Data showed non-normal (non-parametric) distribution. Mann- Whitney U test was used to compare between the two groups then Wilcoxon signed-rank test was used to study the changes after treatment within each group. The significance level was set at $\mathrm{P} \leq 0.05$. Statistical analysis was performed with IBM (IBM Corporation, NY, USA) SPSS (SPSS, Inc., an IBM Company) Statistics Version 21 for Windows.

\section{RESULTS}

The subject flow in this trial was illustrated in a COSORT flow diagram (Figure 1). The means, standard deviations (SD), median and range of endotoxins levels $(\mathrm{pg} / \mathrm{ml})$ and percentage reduction in endotoxins levels (\%) in the two groups are shown in (Table 1 and 2, Figure 2). Mann-Whitney $\mathrm{U}$ test showed there was no statistically significant difference between endotoxins levels in the two groups Pre-operatively, $(\mathrm{P}$-value $=0.422$, Effect size $=0.142$ ), while there was a statistically significant difference between endotoxins levels in the two groups $(\mathrm{P}$-value $=0.004$, Effect size $=0.480)$ Postoperatively, where Group OS showed statistically significantly higher median endotoxins level than Group PN.

Wilcoxon signed-rank test showed a statistically significant reduction in endotoxins levels after treatment in Group OS (P-value $<0.001$, Effect size $=0.880)$ and in Group PN (P-value <0.001, Effect size $=0.931)$. Results showed

a statistically significant difference between the two groups in the percentage reduction of endotoxins levels (Pvalue <0.001, Effect size $=0.598$ ). Group OS showed statistically significantly lower median $\%$ reduction in endotoxins level than Group PN.

\section{Descriptive statistics}

TABLE (1) Descriptive statistics for endotoxins levels (pg/ml) and percentage reduction in endotoxins levels (\%) in the two groups.

\begin{tabular}{|c|c|c|c|c|c|c|}
\hline \multirow{3}{*}{ Group } & Time & Mean & SD & Median & Minimum & Maximum \\
\hline \multirow{3}{*}{ OS } & Pre-operative & 297.9 & 225.4 & 195.7 & 112.6 & 757 \\
\cline { 2 - 7 } & Post-operative & 54.4 & 30.6 & 52.9 & 8 & 116.5 \\
\cline { 2 - 7 } & Reduction \% & 79.3 & 8.1 & 76.8 & 62.1 & 92.9 \\
\hline \multirow{3}{*}{ PN } & Pre-operative & 321 & 403.9 & 182.3 & 107.7 & 1411.8 \\
\cline { 2 - 7 } & Post-operative & 26.1 & 25.2 & 17.5 & 6.6 & 86.4 \\
\cline { 2 - 7 } & Reduction \% & 89.6 & 5.9 & 91.8 & 77 & 96.3 \\
\hline
\end{tabular}


TABLE (2) The median, range values and results of Mann-Whitney $U$ test for comparison between endotoxins levels $(\mathrm{pg} / \mathrm{ml})$ and percentage reduction in endotoxins levels $(\%)$ in the two groups.

\begin{tabular}{|l|c|c|c|c|c|c|}
\hline \multirow{2}{*}{ Time } & \multicolumn{2}{|c|}{ OS } & \multicolumn{2}{c|}{ ON } & \multirow{2}{*}{ P-value } & $\begin{array}{c}\text { Effect size } \\
(\boldsymbol{r})\end{array}$ \\
\cline { 2 - 7 } & Median & Range & Median & Range & \\
\hline Pre-operative & 195.7 & $112.6-757$ & 182.3 & $107.7-1411.8$ & 0.422 & 0.142 \\
\hline Post-operative & 52.9 & $8-116.5$ & 17.5 & $6.6-86.4$ & $0.004 *$ & 0.480 \\
\hline Reduction \% & 76.8 & $62.1-92.9$ & 91.8 & $77-96.3$ & $<0.001 *$ & 0.598 \\
\hline
\end{tabular}

*: Significant at $P \leq 0.05$

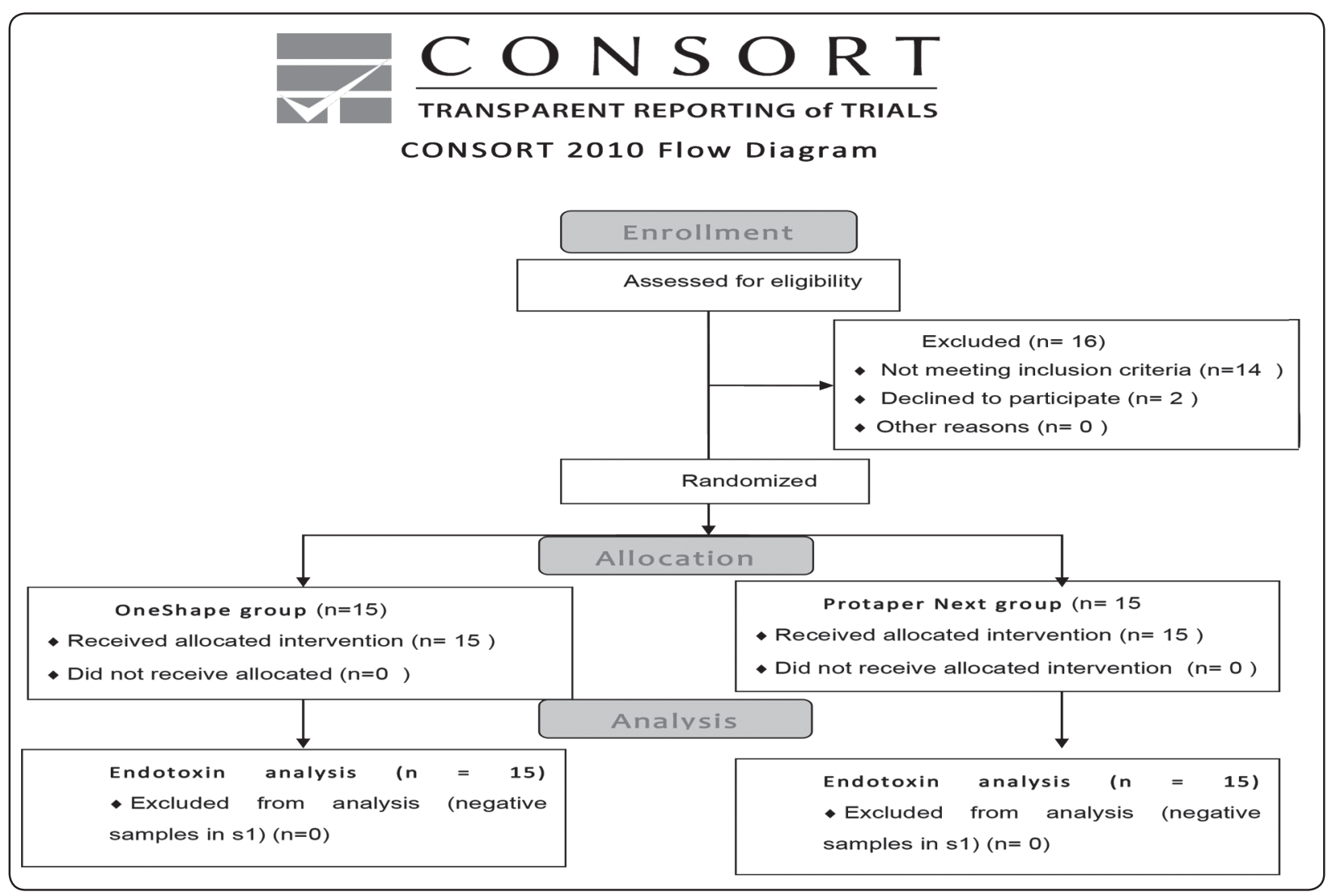

Fig. (1): CONSORT 2010 Flow Diagram 


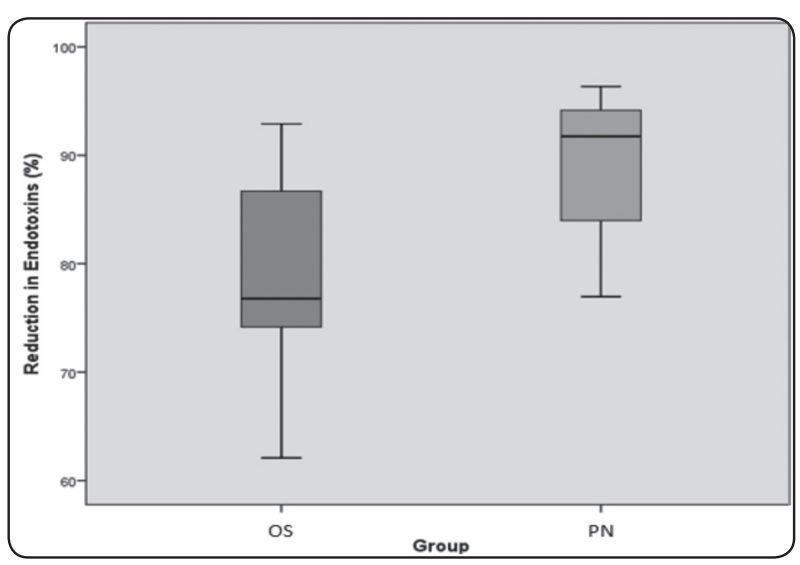

Fig. (2). Box plot representing the median and range values for the percentage reduction in endotoxins levels in the two groups (Group OS and Group PN).

\section{DISCUSSION}

As a result of the medical, political, and economic changes that occurred in the 1990s, randomized clinical trials and evidence-based methods are presently in the forefront of the physician's thinking in the decision-making process for therapeutic 0are the most rigorous way of determining whether a cause-effect relation exists between treatment and outcome and for assessing the cost effectiveness of a treatment ${ }^{[19]}$.

Patient with single-rooted, canal mandibular premolars were included ${ }^{[20,21]}$, to avoid the variations in the root canal system of multirooted teeth that may complicate the disinfection of all the root canal spaces and may compromise the results ${ }^{[22]}$, then the apical preparation was standardized to a size 30 for all canals, as various studies had reported that the apical size of the prepared canal is an important factor in effective bacterial reduction ${ }^{[23,24]}$.

The primary endodontic infection is multimicrobial, mostly gram-negative bacterial species $^{[25]}$, with endotoxins present on their outer layers ${ }^{[5]}$, which can extend into the periapical tissue, leading to an inflammatory process. Thus, the primary objective of the root canal treatment should be the elimination of endotoxins ${ }^{[16]}$. Recently the interest in using a single-file NiTi systems to pre- pare the whole root canal has been increased, related to its ability to shorten the treatment session for both the operator and the patient, and may be cost-effective.

However, evidence as to the cleaning and disinfecting abilities of these systems is not sufficient. Furthermore, there was no significant difference in bacterial reduction when single-file systems were compared with manual techniques ${ }^{[7,8]}$ or reciprocating single or continuously rotating multi-file systems ${ }^{[26]}$. In addition, there are few studies on the use of different single-file systems in continuous rotation motion movement, thus more studies are necessary to assess these instruments. Therefore, the aim of the present study was to evaluate the effectiveness of OneShape as a single-rotary file and to compare it with the Protaper Next rotary system regarding the percentage of endotoxins reduction.

The sandwich technique was used to quantify a specific sample antigen, where the well surface is treated with a known amount of bound antibody to capture the needed antigen. A specific primary antibody is then applied that "sandwiches" the antigen. Enzyme-linked secondary antibodies are added that bind to the primary antibody. Unbound antibody-enzyme conjugates are washed off. Substrate is applied and is enzymatically converted to a color that can be later quantified. One of the advantages of using a purified specific antibody to capture antigen is that it eliminates the necessity to purify the antigen from a mixture of other antigens, thus simplifying the assay and elevating its specificity and sensitivity ${ }^{[27]}$.

Our results demonstrated significant reduction in the endotoxins concentration after root canal instrumentation using Oneshape single-file system, which was in agreement with ${ }^{[8,28,29]}$, who reported significant bacterial load reduction after mechanical preparation using Oneshape single-file system, this may be attributed to its asymmetrical movement, in addition to other features including the variable cross-section and longer pitch, which are claimed for 
the reduction in the preparation time, improving the efficiency of cleaning, reducing the bacterial charge and the amount of apically extruded debris ${ }^{[14]}$.

Regarding the ProTaper Next group, a significant endotoxin reduction was also observed after mechanical preparation, which was in consistent with previous studies addressing significant bacterial reduction after root canal instrumentation using ProTaper Next ${ }^{[9,29]}$.

This might be related to the offset rectangular cross-sectional design of ProTaper Next, which generates a wave of motion during rotation known as a "swaggering effect". So, it engages dentin on larger circumference than its own ize. As a result, it can load and remove more debris with less possibility of lateral compaction, compared with a similar-sized file with a symmetrical mass and axis of rotation ${ }^{[30]}$.

To our knowledge, this is the first clinical trial comparing the effectiveness of OneShape single-file system with that of ProTaper Next rotary system in endotoxin reduction. Our study reported significant difference between both groups, where the percentage of endotoxin reduction was higher with the Protaper Next system, thus the null hypothesis was rejected, this was in consistent with the result of ${ }^{[31]}$ who reported that the single-file F2 in the ProTaper system technique have similar cleaning results compared with the full range of the ProTaper instruments in round canals, while its performance was less efficient in oval canals.

Moreover, the result was in contrast with that of previous studies comparing disinfection effectiveness between single- and multi-file systems ${ }^{[7,26,31]}$, which could be attributed to the use of different file systems and different kinematics.

\section{CONCLUSION}

Within the limitations of our study it can be concluded that Protaper Next rotary system was more effective in endotoxins reduction from mandibular premolar with necrotic pulp.

\section{REFERENCES}

1- Nair PN, Henry S, Cano V, Vera J (2005). Microbial status of apical root canal system of human mandibular first molars with primary apical periodontitis after "one-visit" endodontic treatment. Oral Surg Oral Med Oral Pathol Oral Radiol Endod;99(2):231-52.

2- Fabricius L, Dahlén G, Holm SE, Möller AJ (1982). Influence of combinations of oral bacteria on periapical tissues of monkeys. Eur J Oral Sci.;90(3):200-6.

3- Nair PN (2004). Pathogenesis of apical periodontitis and the causes of endodontic failures. Critical Reviews in Oral Biology \& Medicine.;15(2):348-81.

4- Stashenko P (1990). The role of immune cytokines in the pathogenesis of periapical lesions. Dent Traumatol.; 6(3):89-96.

5- Dahlen G, Bergenholtz G (1980). Endotoxic activity in teeth with necrotic pulps. J Dent Res.;59(6):1033-40.

6- Schein B, Schilder H (2006). Endotoxin content in endodontically involved teeth. J Endod;32(4):293-5.

7- Machado ME, Nabeshima CK, Leonardo MF, Reis FA, Britto ML, Cai S (2013). Influence of reciprocating singlefile and rotary instrumentation on bacterial reduction on infected root canals. Int Endod J;46(11):1083-7.

8- Nabeshima CK, Caballero-Flores H, Cai S, Aranguren J, Britto ML, de Lima Machado ME (2014). Bacterial removal promoted by 2 single-file systems: Wave One and One Shape. J Endod;40(12):1995-8.

9- Tewari RK, Ali S, Mishra SK, Kumar A, Andrabi SM, Zoya A, Alam S (2016). Mechanical reduction of the intracanal Enterococcus faecalis population by Hyflex CM, K3 XF, ProTaper Next, and two manual instrument systems: an in vitro comparative study. J invest and clin dent;7(2):168-73.

10- Peters OA (2004). Current challenges and concepts in the preparation of root canal systems: a review. J Endod; 30(8):559-67.

11- De-Deus G, Brandão MC, Barino B, Di Giorgi K, Fidel RA, Luna AS (2010). Assessment of apically extruded debris produced by the single-file ProTaper F2 technique under reciprocating movement. Oral Surg Oral Med Oral Pathol Oral Radiol Endod.;110(3):390-4.

12- Elnaghy AM (2015). Response: Cyclic fatigue resistance of ProTaper Next nickel-titanium rotary instruments. Int Endod J;48(11):1101. 
13- Liu R, Hou BX, Wesselink PR, Wu MK, Shemesh H (2013). The incidence of root microcracks caused by 3 different single-file systems versus the ProTaper system. J Endod; 39(8):1054-6.

14. Dhingra A, Kochar R, Banerjee S, Srivastava P (2014). Comparative evaluation of the canal curvature modifications after instrumentation with One Shape rotary and Wave One reciprocating files. J conser dent;17(2):138.

15- Martinho FC, Gomes AP, Fernandes AM, Ferreira NS, Endo MS, Freitas LF, Camões IC (2014). Clinical comparison of the effectiveness of single-file reciprocating systems and rotary systems for removal of endotoxins and cultivable bacteria from primarily infected root canals. J Endod;40(5):625-9.

16- Martinho FC, Chiesa WM, Marinho AC, Zaia AA, Ferraz CC, Almeida JF, Souza-Filho FJ, Gomes BP (2010). Clinical investigation of the efficacy of chemomechanical preparation with rotary nickel-titanium files for removal of endotoxin from primarily infected root canals. J Endod; 36(11):1766-9.

17- Xavier AC, Martinho FC, Chung A, Oliveira LD, Jorge AO, Valera MC, Carvalho CA (2013). One-visit versus twovisit root canal treatment: effectiveness in the removal of endotoxins and cultivable bacteria. J Endod;39(8):959-64.

18- Kennedy HL (1999). The importance of randomized clinical trials and evidence-based medicine: A clinician's perspective. Clin Cardiol;22(1):6-12.

19- Sibbald B, Roland M (1998). Understanding controlled trials. Why are randomised controlled trials important?. BMJ: Br Med J.; 316(7126), 201.

20- Esk M, Sadrhaghighi H, Rahmani M, Majd NM, Sadighi A (2012). Comparison of two mechanical instrumentation techniques in reducing root canal bacterial population. Afr J Microbiol Res;6(15):3635-8.

21- Matos Neto M, Santos SS, Leão MV, Habitante SM, Rodrigues JR, Jorge AO (2012). Effectiveness of three instrumentation systems to remove Enterococcus faecalis from root canals. Int Endod J;45(5):435-8.
22- Vossoghi M, Vossoghi M, Shahriari S, Faramarzi F, Mashouf RY, Farhadian M (2016). Efficacy of a novel rotary system in reduction of intracanal bacteria: An in Vitro Study. Iran Endod J.;11(3):219.

23- Ørstavik D, Kerekes K, Molven O (1991). Effects of extensive apical reaming and calcium hydroxide dressing on bacterial infection during treatment of apical periodontitis: a pilot study. Int Endod J;24(1):1-7.

24- Siqueira JF, Lima KC, Magalhães FA, Lopes HP, de Uzeda M (1999). Mechanical reduction of the bacterial population in the root canal by three instrumentation techniques. J Endod; 25(5), 332-335.

25- Siqueira Jr JF, Alves FR, Rôças IN (2011). Pyrosequencing analysis of the apical root canal microbiota. J Endod;37(11):1499-503.

26- Neves MA, Provenzano JC, Rôças IN, Siqueira Jr JF (2016). Clinical antibacterial effectiveness of root canal preparation with reciprocating single-instrument or continuously rotating multi-instrument systems. J Endod;42(1):25-9.

27- Gan SD, Patel KR (2013). Enzyme immunoassay and enzyme-linked immunosorbent assay. J Invest Dermatol;133(9):e12.

28- Dagna A, Arciola CR, Visai L, Selan L, Colombo M, Bianchi S, Poggio C (2012). Antibacterial efficacy of conventional and single-use Ni-Ti endodontic instruments: an in vitro microbiological evaluation. Int $\mathrm{J}$ Artif Organs;35(10):826-31.

29- Karataş E, Gültekin E, Arslan H, Kırıcı DÖ, Alsancak M, Topçu MÇ (2015). Evaluation of instrumentation systems in reducing E. faecalis from root canals: TF adaptive and ProTaper next versus single file systems. Int J Artif Organs;38(3):161-4.

30- Ruddle CJ [cited on 25 Nov 2013]. Available from: http:// dentistrytoday. com/endodontics/8865-theshapingmovement- fifth-generation-technology.

31- De-Deus G, Barino B, Zamolyi RQ, Souza E, Júnior AF, Fidel S, Fidel RA (2010). Suboptimal debridement quality produced by the single-file F2 ProTaper technique in ovalshaped canals. J Endod;36(11):1897-900. 